Prior's paradigm for the study of time and its methodological motivation

Hasle, Per Frederik Vilhelm; Øhrstrøm, Peter

Published in:

Synthese

DOI:

10.1007/s11229-016-1161-6

Publication date:

2016

Document version

Publisher's PDF, also known as Version of record

Document license:

Unspecified

Citation for published version (APA):

Hasle, P. F. V., \& Øhrstrøm, P. (2016). Prior's paradigm for the study of time and its methodological motivation. Synthese, 193(11), 3401-3416. https://doi.org/10.1007/s11229-016-1161-6 


\title{
Prior's paradigm for the study of time and its methodological motivation
}

\author{
Per Hasle $^{1}$. Peter Øhrstrøm²
}

Received: 30 March 2016 / Accepted: 11 July 2016 / Published online: 12 August 2016 (C) The Author(s) 2016. This article is published with open access at Springerlink.com

\begin{abstract}
A. N. Prior's writings should obviously be studied already for historical reasons. His inventions of modern temporal logic and hybrid logic are clearly important events in the history of logic. But the enduring importance of studying his works also rests on his methodological approach, which remains highly relevant also for systematical reasons. In this paper we argue that Prior's formulation in the 1950s of a tense-logical paradigm for the study of time should be understood in the light of at least three other principles or perspectives which were manifest already in his studies during the 1940s and further developed in the 1950s: (1) his emphasis on the value of interdisciplinary studies, (2) his reflections on formalisation and (3) his view of the role of symbolic logic in conceptual studies and in the philosophy of science. Our investigation into Prior's basic tenets and principles makes extensive use of Prior's Nachlass. It is thereby also exemplified how his correspondence and unpublished papers contain important information for a deeper understanding of Prior's paradigm for the study of time.
\end{abstract}

Keywords A. N. Prior · Temporal logic · Interdisciplinary studies · Formalisation

A. N. Prior's most important works were written in the period from 1953 to his untimely death in 1969. However, recently his earlier works have attracted growing attention (Hasle 2012; Grimshaw 2002, 2013; Jakobsen 2013). It has become clear that his work preceding his first formulation of formal tense-logic in $1953 \mathrm{had}$ a much stronger

\footnotetext{
$凶$ Per Hasle

per.hasle@hum.ku.dk

1 University of Copenhagen, Copenhagen, Denmark

2 Aalborg University, Aalborg, Denmark
} 
influence on his tense-logical paradigm for the study of time than has previously been assumed.

In his own day, Prior's papers and books were clearly received as important contributions to logic and philosophy. However, much has happened in these fields since then, and a number of Prior's ideas and suggestions have later been developed further. Many of the specific problems that Prior worked on should now be studied in the light of later discoveries and findings. Given that this is so, why should we still bother with studying Prior's original writings? Clearly, a partial answer is the desire to obtain a better and deeper understanding of the history of logic and philosophy. After all the 1950s and 1960s were very important periods in the development of these fields - not least because several kinds of logical studies were born in this period. Prior should in fact be seen as the founding father of both modern tense logic and hybrid logic; see (Blackburn 1993; Braüner 2011) and (Øhrstrøm and Hasle1995, p. 167 ff.), and his work was evidently also very important in the early development of modal logic and deontic logic. Prior was very much involved in the discussions of that era between leading logicians and logic-oriented philosophers. This engagement took place via publications of course but notably also through his extensive correspondence. Correspondence was probably even more important to Prior than to most other actors in the field. Living and working in New Zealand until the end of 1958, Prior's opportunities for participating in meetings and conferences were limited, and exchange of letters was vital (cf. Prior 2003a). Anyone who wants to study the development of modern philosophical logic will find an unusually rich source in Prior's writings and especially in the Nachlass. For this reason alone, it certainly makes sense to study the works of A. N. Prior and to make his Nachlass-i.e. his many unpublished papers and his correspondence - available for further study. However, in addition to this historical motivation we suggest that a more general and conceptual reason can be given for the continuing systematic interest in Prior's philosophy and logic. Since Prior in his writings introduced a powerful and attractive paradigm for the study of time it is worth studying the methodological underpinnings of the paradigm, and highly probable that such studies of his work can stimulate future developments of the paradigm and the use of it. The enduring importance of studying the works of A. N. Prior has to do with the fact that this can lead to a better practice in the exploration of the concept of time and it various aspects. And in fact, exploration of other concepts and phenomena can well be based on the same principles. In the following we identify and investigate three important principles or perspectives that are essential for understanding the tense-logical paradigm for the study of time. These can all be traced back to Prior's works in the 1930s and the 1940s and are strongly supported through the Nachlass material. The principles in question are, however, not mutually independent. In fact, it turns out that they are closely linked to one another, and their interplay gives rise to the essential character of the paradigm. The underlying assumption of these principles or perspectives is that a rational approach is possible and attractive even when it comes to the study of existential aspects and questions in life. Prior's methodological approach provides a bridge between the "two cultures" of the humanities and the exact sciences. Prior translated concepts and considerations rooted in philosophy and even theology into formal logic, and conversely, applied formal and exact methods of study to realms of life and thought "normally" studied through more discursive methods. 
Nevertheless, there are as we shall see strong indications that Prior did not strive to completely conflate or merge the two domains, and in fact did not believe this to be entirely possible. But on the Priorean view, they can and should be brought together so far as possible and furthermore in ways where it would traditionally not be thought possible.

\section{The value of interdisciplinary discussions}

As a young man, 18 years of age, Prior became a member of the Presbyterian Church. In 1935-1936 he was even training to be an ordinand for the ministry within the church. He remained an active member of the church till the late 1950s. During this period he published a number of theological papers (see for instance Prior 1934a, b, 1935, 1946, 1947, 1955 and 1959). Although he (around 1958/59, after moving to England) left the Presbyterian Church and never joined any other denomination, he retained his intellectual interest in theological thoughts. It should also be mentioned that his most famous theological paper, "The formalities of omniscience", was published in (1962). In some of his theological papers from the 1930s and 1940s, one can detect some of the methodological leanings and values which later became integral parts of his paradigm for the study of time.

It is well known that Prior went through a deep crisis of belief in 1942. A recently uncovered diary entry (2014c) has added significant perspectives to our understanding of Prior's religious crisis and the relation between theology and other themes in Prior's work (cf. Jakobsen 2013). Generally speaking, it appears from (Prior 2014c) that theology became a kind of "intellectual test-bed" for him alongside other intellectual issues. Since his teenage years he had been interested in a number of other topics including linguistics, history, ethics, psychoanalysis, social science, astronomy, biology and physics (see Grimshaw 2002). It is clear that he brought these rather different subject areas to bear on each other, thereby bringing them into constructive interaction-in a kind of dialogue, or as different perspectives on certain subject matters. He clearly believed in the importance of having a rational dialogue between the various disciplines and perspectives. Actually, he wrote two papers in 1942 in which he "set up" possible discussions on theological matters between representatives of different disciplines and views (Prior 1942, 2012). In this way he demonstrated that although it may be very difficult to settle the various questions at stake, and although the participants in the debate may use rather different vocabularies and means of expression, there is an important value in the mere bringing views and arguments from different positions and approaches to bear on one and the same issue. To Prior this also constituted a democratic value. (Mary Prior once remarked to Per Hasle that Prior's continuing references to intellectuals from much earlier times, especially Antiquity and the Middle Ages, also had to do with his view that it was their democratic right to have their views brought forward; personal communication).

It is obvious that the significance of various and different positions on conceptual questions becomes much clearer when these are presented in terms of a rational discussion. A topic may actually be studied in an illustrative manner by confronting the various positions and views that are relevant in relation to the topic in question. In many 
cases there is a need for a number of rather different perspectives in order to obtain a proper understanding of a certain topic. It appears that Prior kept subscribing to this methodological value of rational and what we would nowadays call interdisciplinary discussion throughout his entire philosophical career.

Prior worked in an Aristotelian tradition according to which human reasoning is the main instrument ("Organon") "by which the sciences proper are pursued" (Prior 2016 , p. 6). The fact that the same kind of rationality underlies any science and indeed any intellectual discipline is also what makes interdisciplinary discussion possible. When we study topics that occur in several disciplines (such as the concept of time), it should be possible to establish a common language in terms of which the rational debate regarding the topic can be expressed. Much of Prior's work in tense logic can and should be understood as an attempt at formulating a precise and common language for cross-disciplinary discussions of time (cf. Øhrstrøm 2011). Actually, along with this work he tried to maintain a close dialogue with friends and colleagues who disagreed with him on the various issues regarding time. He had a strong belief in the value of this kind of rational communication across disciplines, opinions and world views. From the Prior collection at the Bodleian Library we know that he was extremely active in his correspondence with other researchers around the world. One of the persons with whom he corresponded very frequently was Jack Smart in Australia, who defended the so-called B-theory of time and had become famous for his view that the passage of time is an illusion (Smart 1949). Prior disagreed strongly with Smart on many important points, but this only made the correspondence with Smart more valuable to Prior. It seems that during the 1950s Prior would hardly submit a paper for publication without first having obtained Jack Smart's comments on it.

\section{Prior's view on formalisation}

Prior's ideas on the nature and the role of rationality in interdisciplinary discussions give rise to a very general question about formalisation: Can all questions about reality be studied with formal methods? Or are there aspects of reality that are not amenable to this approach? Ethics, for example, is often viewed as being within the realm of subjectivity and beyond the scope of rational discussion. Such perceptions notwithstanding, Prior was very interested in the formalisation of ethical argumentation and wanted to investigate to what extent ethics and ethical reasoning can be formalised. He found that it makes sense to look for "the logic of obligation", although he rejected the idea that all aspects of such a logic follow from the conceptual structure of the concept of obligation. In Prior's opinion we have to see obligation in a much broader context. As he stated in his paper, The logic of obligation and the obligations of the logician, "we must think not only of its immediate subject-matter (obligation), but must see it taking its place in the larger company of formalised systems and absorbing something of their style." (2014f, p. 2).

In general, Prior wanted to formalise as much as at all possible, but at the same time he acknowledged that there are limits to formalisation. In his opinion, it would be very important to have a formal language in terms of which structures of reality can be discussed. He wrote: 
... it is important to "formalise" as much as we can, i.e. to state truths about things in a rigorous language with a known and explicit structure. It is also important to pay attention to the structure of our language in order to expose and eliminate philosophical "pseudo-problems".... (2014b)

During his crisis of belief in 1942, Prior decided to continue his studies of "theological systems". At this specific point of time he even described himself as a person who "collected theological systems as another man collects pictures" (Prior 2014c). The notion of a system had a key role to play in his understanding of scientific and philosophical research. In his opinion theological systems were important, since they capture the essential structure of the theological reasoning in question. Even if crucial concepts and tenets of theology are regarded as illusory (as indeed they explicitly were in Prior (2014c)), theological investigations and discussions could full well be performed in a rational manner. Any system would be based on a limited vocabulary or a restricted language (a discourse) in terms of which some fundamental claims (doctrines) and some rules of inference are stated. It turns out that there is an interesting similarity between systems as they are used in rather different disciplines such as theology, physics and law. In all cases the systems will express how reasoning within the actual field can be carried out. The crucial challenge in formalisation would be to establish a useful system for the subject in question.

It is unclear how long Prior's 1942 conviction (cf. 2014c) lasted, but it should be noted that he remained an active member of the Presbyterian Church. During the 1940s Prior was very interested in the notions of predestination and determinism. As a Presbyterian he defended the doctrine of predestination. However, gradually this position became increasingly problematic to him, and he became more and more interested in finding a way to limit determinism in order to leave some conceptual room for human freedom (see 2014d, 2014e). Eventually, he left the Presbyterian denomination and proclaimed his belief in what he called real freedom:

One of the big differences between the past and the future is that once something has become past, it is, as it were, out of our reach - once a thing has happened, nothing we can do can make it not to have happened. But the future is to some extent, even though it is only to a very small extent, something we can make for ourselves.... (2014a)

Prior was aware of the fact that others had tried to establish a philosophical explanation that would allow for some human freedom. One important contribution was Bergson's book from 1889 Essai sur les données immédiates de la conscience, which was published in an English translation as Time and Free Will (1950). In his discussion Bergson actually came close to the idea of branching time although it was not presented with reference to logic or in a manner congenial to logicians. Prior did not find Bergson's ideas satisfactory, mainly because it was presented without any attempt at more precise formalisation. In an undated note he wrote:

And I think it important that people who care for rigorism and formalism should not leave the basic flux and flow of things in the hands of existentialists and Bergsonians and others who love darkness rather than light, but we should enter 
this realm of life and time, not to destroy it, but to master it with our techniques.

(Undated note; kept in the Prior Collection, Box 6, Bodleian Library, Oxford.)

Clearly, Prior found that problems of time and free will have to be studied in a much more precise language than demonstrated by Bergson. The attempts at finding formal models of limited determinism, and respectively, indeterminism, became very important for him during the 1950s and the 1960s. As mentioned above he constructively proved that tense logic can in fact give rise to formal models of this kind and thereby also to a formal language for interdisciplinary discussions of time (cf. Øhrstrøm 2011, 2016).

Prior rejected the idea that a topic might have a structure, a logic, which at the same time forbids formalisation. For instance, it seems rather strange to claim that there is a logic of obligation that is unformalisable (Øhrstrøm et al. 2012). Considering this problematic idea of an unformalisable logic of obligation, he responded: "At this point the logician is surely bound by the oath of his calling to dig his toes in, and to be ready to "fight on the beaches'." (2014f, p. 16) Prior's view seems to be that if something has a structure, an order, then it will be the obligation of the logicians to work on its formalisation and never to give up.

Prior realised, however, that there could be parts of aspects or reality which we may not be able to formalise. He explicitly acknowledged that some domains are more amenable to formalisation than others, indeed leaving open the possibility that some domains/questions are beyond the scope of formalisation:

But I don't think that there's anything better to be said here than that some subjects do in fact have more order, more structure, more form, than othersthat some subjects are more capable of being handled by means of a formal symbolic calculus - and in these cases it is more proper than in others to speak of a 'logic' of the thing. (Prior 1976, p. 129)

In a modern, digital context this question acquires a special and acute importance. Quite apart from any limitations to effective formalisation implied by Gödel's and Turing's theorems, there may be other kinds of qualitative limitations. And since mechanistic implementation will presuppose some sort of formalisation, the discovery of areas of reality that lie beyond the limits of formalisation would seem to exclude these areas of reality from the scope of computational methods. For these reasons, we should certainly discuss the questions of formalisation and its limitations. Again, it seems obvious that Prior's reflections on this topic will serve as a useful inspiration to anyone who wants to investigate the power of as well as the limitations to formalisation.

\section{The use of symbolic logic in conceptual studies}

Prior held that having a formalisation of a subject expressed in a formal and symbolic language can be extremely helpful in philosophy and in all kinds of conceptual studies. But exactly how can such studies benefit from the fact that there is a formalisation of the subject in terms of symbolic logic? 
Prior found that symbolic logic is essential when it comes to carrying out his ambitions regarding formalisation. Logical systems are based on a formal language, some axioms and some rules of inference. They are much clearer and more precise than systems in other disciplines, and it will be a great advantage if we can express the topic we want to study in terms of a logical system. In this connection it is worth recalling, however, that for example theological systems could be the basis of and subject for rational discussion. The same could without doubt be said for discussions within fields such as history, literary theory, and so on. ${ }^{1}$ But formalisation in so far as possible makes discussion much safer and more transparent. For this reason Prior's view was that logic in a broad sense should be used as much as possible, not only within various disciplines, but also in order to establish a crucial link between the disciplines-a common ground for discussion. In this way we may obtain a much deeper understanding of the topic we are facing. It was Prior's ambition to take the analysis of reality and existence as far as he could. If possible he would prefer to formalise the topics in question in terms of symbolic logic. One famous example of how this can be done was his work on "The Formalities of Omniscience" (1962) in which he in a very careful manner explained how the classical doctrine of divine foreknowledge can be represented in terms of symbolic logic and how its consequences can be analysed. In fact, Prior's analysis of this example contributed significantly to the development of tense-logic. He clearly demonstrated that formalisation in terms of symbolic logic can lead to a very importation clarification. However, Prior rejected formalism when understood as "the theory that Logic is just about symbols and not about things" (2014b). According to him this view is plainly false. Logic should be conceived as a formal language that makes it possible to discuss, investigate and reason about all important aspects of reality - to the extent that the domain in question is formalisable. However, in most cases logic cannot offer the final decision on what to believe. Prior's interest in interdisciplinary studies involved a certain picture of the role of logic in science and in academic study as such. Prior explained that the logician can like a lawyer investigate various possible conceptions and their consequences. In his own words:

The logician must be rather like a lawyer. ... He must tell his client what the consequences of a given choice will be ... and what alternatives are open to him; but I doubt whether he can, qua logician, do more. (1967, p. 59)

This means that in most cases, what the logical analysis can give us is a list of possible positions each of which is then carefully described in terms of its consequences. This of course may show that one system has consequences which may be harder to accept than another one, but this analysis rarely can establish a decision by itself. The user of the logical analysis has to decide which position he or she considers most convincing or rewarding.

In contrast to classical logic, including Fregean logic with its atemporal and extensional character, Prior clearly wanted a renewed kind of logic with which he could treat no only traditional logical matters, but also existential questions in life. In the unpublished and undated note mentioned above he explained what he was looking for:

\footnotetext{
1 Inspired by Karl Barth's dogmatics Prior found that theology can in fact be formulated very much like a logical system.
} 
Perhaps you could call my logic a mixture of Frege and Kołakowski. I want to join the formal rigorism of the one with the vitalism of the other. Perhaps you regard this as a bastard mixture-a mésalliance. I think it is a higher synthesis. (undated note; kept in the Prior Collection, Box 6, Bodleian Library, Oxford).

This is a very interesting statement. Like Frege, Prior saw a relation between formal logic and formal aspects of natural language. Moreover, he had devoted chapter VI of his Time and Modality (1957) to the development of a "Modal Logic in the Style of Frege". On the other hand, Prior was also deeply involved in considerations regarding existential matters. Leszek Kołakowski (1927-2009) was a Polish philosopher and historian of ideas, who in the course of his career developed from a position as a Marxist philosopher into a dissenter, defending with increasing vigour the importance of human freedom. The obvious agreement between Prior himself and Kołakowski on this point notwithstanding, the reference to Kołakowski is quite remarkable. Prior in general made few references to contemporary Continental philosophy or its nineteenth century forerunners like Bergson, and in spite of his strong Socialist convictions he never exhibited interest in Marxism as a philosophical system. (Asked directly about Prior's lack of interest in Marxism, Mary Prior once stated that in spite of his Socialism, Marxism and especially its idea of "dialectics" never held any attraction for Prior as a logician. Personal communication with Per Hasle). Kołakowski had already in the late 1950s criticized the Marxist notion of "historical determinism", and from that time onwards he further elaborated ideas of human freedom (cf. Kołakowski 1956). Unfortunately, since it has not been possible to date the note with this reference, we cannot know which stage of Kołakowski's thought so inspired Prior, or for that matter, how thoroughly. So we must refrain from further speculation. But in any case, Prior wanted-just like Kołakowski-to develop a model taking human freedom into account. As a mixture of Frege and Kołakowski the formal logic that Prior wanted to develop should be rigorous and should also represent the idea of alternative futures between which we as human beings can exert some freedom of choice. As we shall see, his analysis of the temporal aspects of reality in "The formalities of omniscience" (1962) and the further exploration of related themes in Past, Present and Future (1967) and in Papers on Time and Tense (2003a; $2003 \mathrm{~b}$ ) led him to the formulation of some very important and basic positions regarding time and existence.

As has become evident, Prior did not claim that logical analysis will answer all philosophical questions related to the study of a subject. However, logical analysis will normally lead to a list of possible positions regarding the subject in question. Furthermore, logical analysis shows what follows from the various possible positions. But what if a person when confronted with the consequences of a certain position, as they follow from logical analysis, wants to retain the position but will not accept the consequences? That is, if the person does not want to accept the logical consequences of the position he or she has chosen? Prior maintains that in such cases there is nothing more the logician can do to help his client. In Prior's own words:

To ask a logician to do anything else with it-above all, to ask him to throw it away-is to ask him to turn aside from the one opportunity that has yet offered 
itself of effecting the same kind of spectacular simplification in this field that has marked his progress in others. It is asking him to do second-rate work; and to an honest craftsman that is the same as asking him to down tools and go home. (2014f, p. 18)

\section{The Priorean paradigm for the study of time}

Few concepts seem more to call for interdisciplinary discourse than the concept of time. Almost all scientific disciplines contribute to the understanding of time. As the preceding discussion suggests, it should then be useful to find a formal languageand that is, a representation in terms of symbolic logic — which makes it possible to study temporal problems across disciplines. In particular, it might be possible in this way to deal with the classical problem of time and free choice as well as the problem regarding the tension between dynamic and static time.

In 1953 Prior devised the first version of a formal language which could give rise to a paradigm for the study of time. This language was based on so-called tense logic. Prior himself described how he first arrived at the idea of a logic of tenses in 1953 from reading a footnote by John Findlay, suggesting that there could be a logic of tenses (cf. Øhrstrøm and Hasle 1995, pp. 170-171). Prior's modesty in attributing the idea to Findlay notwithstanding, it is clear that this strong and apparently immediate inspiration from Findlay's suggestion was only possible on the basis of preceding thoughts and studies. For one thing, Prior had attended a large logic conference in Sydney in 1951, which had drawn his interest toward modern symbolic logic. It had also provided Prior with his first thorough acquaintance with modal logic, a discipline obviously addressing problems related to temporality.

There was one further reason why tense-logic caught Prior's attention. This was the fact that tense-logical formalism could be applied to the study of some metaphysical and theological problems which had attracted Prior's interest for several years. As an active member of the Presbyterian Church during the 1930s, 1940s and 1950s, Prior had taken a particular interest in discussions about determinism, predestination, and free choice. Prior had for many years been preoccupied with the problems arising from the Calvinistic doctrine of predestination and the various ideas of human freedom, problems that are in many ways intrinsically temporal in nature (see Hasle 2012). The culmination of this work was his paper "The formalities of omniscience" (1962) mentioned above. It turns out that this work conceptually and structurally is closely related to the so-called Master argument of Diodorus which was in fact one of the first tense-logical arguments that caught Prior's attention. He kept returning to the Diodorean argument for more than 10 years until his version of the argument found its most elaborated form in his book, Past, Present and Future (1967, p. 32 ff.). In this way he demonstrated how his logical approach can clarify fundamental questions regarding time and existence that he had been struggling with since the 1940s.

There can be little doubt that Findlay's footnote caught Prior's attention in 1953 not only because it suggested a new logical system, but also because this idea implied an approach to the study of time that Prior found very attractive. He later expressed his general view on time in the following way: 
I believe that what we see as a progress of events is a progress of events, a coming to pass of one thing after another, and not just a timeless tapestry with everything stuck there for good and all... (Prior 2014a)

Using a logic of tenses, it would be possible to describe time from this "inner" perspective according to which the passage of time is real. The conceptual framework of tense logic reflects the basic human perspective of past, present and future, and makes it possible to take this perspective into account in a very precise manner. Tense logic gave rise to a new paradigm for the study of time, according to which the understanding of time should be based on what McTaggart (1908) had termed the A-series - past, present and future-as opposed to the B-series (i.e. a description of time as series of instants ordered by a before-after relation).

Prior's tense-logical paradigm for the study of time was often challenged, already in his own day. In an undated note written as a reflection after giving a lecture, Prior wrote:

A wants me to relativise my tenses to dates. It seems to me that behind this request there is a metaphysics. Behind this request there is the idea that the whole of time is absolutely there with all these dates, and all events and processes just are located in various parts of this giant fixed frame. I do not believe this-I think this way is to treat all time as if it were already past. I don't believe this. I don't believe that events and processes are; rather events happen (and then come to have happened) and processes go on (and then come to have gone on), and even this is an abstraction - the basic reality is things acting. But even in this flux there is a pattern, and this pattern I try to trace with my tense-logic; and it is because this pattern exists that men have been able to construct their seemingly timeless frame of dates. Dates, like classes, are a wonderful and tremendously useful invention, but they are an invention; the reality is things acting. .... This is just a postscript to last night's lecture. (Undated note; kept in the Prior Collection, Box 6, Bodleian Library, Oxford).

This seems to be a very clear way of formulating the paradigm he had in mind: Prior wanted to trace the reality of time, including the reality of its passage, using his tense-logic. According to him, time should be conceived fundamentally in terms of the A-series. However, he also allowed that the B-series concepts are important. Theories in the physical sciences theories which involve temporal aspects are usually formulated in terms of instants organized as an ordered series. Clearly, the new tenselogical paradigm has to take on board and somehow account for the notion of series of instants ordered by a before-after relation. To allow for this picture yet without dispensing with his basic A-series point of view, Prior found ways of enlarging tense logic such as to comprise both pictures-thereby in effect inventing what has later come to be known as hybrid logic, although he did not use this term himself. In 1967, Prior suggested that instants could be understood as a special class of propositions with a number of very special properties, calling such instants "world-states" (Prior 1967, pp. 77ff. \& 187ff.). In the paper Tense Logic and the Logic of Earlier and Later (Prior 2003a, p. 117 ff.), he described four grades of tense-logical involvement. The paper developed the idea of instantaneous world states (instant propositions) in great 
detail, showing how B-series notions can be embedded in an A-series framework containing such instant propositions (corresponding to what he called the 3rd and 4th grade of tense-logical involvement). Another way of formulating these results is to say that Prior herein showed how the B-series logic can be given an interpretation within tense-logic. This was also the first systematic presentation of what has come to be known as hybrid logic (Blackburn 1993; Braüner 2011).

In developing his tense-logical approach to time, Prior also made use of the notion of branching time, which had first been suggested to him by Saul Kripke in 1958 (cf. Ploug and Øhrstrøm 2012). However, it seems that Prior accepted this notion with some hesitation, since it strongly resembles the "timeless tapestry with everything stuck there for good and all..." (witness the standard "tree-like" graphical representations of branching time). Branching time is more closely related to a B-series point of view than to the proper inner perspective of time. Nevertheless, branching time is highly useful for illustrating some of the philosophical problems of the logic of time. In fact, the Ockhamistic and the Peircean solutions mentioned give rise to two different interpretations of branching time. In the later development of Prior's tenselogical paradigm for the study of time other interpretations have been developed, e.g. the Molinistic solution that may be seen as a further elaborations of the Ockhamistic solution (see Øhrstrøm 2014; Borghini and Torrengo 2013).

In a letter to Prior dated Oct. 13, 1958, Saul Kripke argued that in scientific discourse we should prefer a tenseless approach to time (i.e. the B-series) and that there is no need to involve tenses in this discourse. Furthermore, he pointed out that the special theory of relativity poses a serious challenge to the tense-logical approach to time. On Oct. 27, 1958, Prior responded in a letter to Kripke that according to his view there is at least one important aspect of reality that cannot be stated in a tenseless language, namely indeterminism. He wrote:

I do not see how indeterminism can be expressed in a tenseless language at all. For indeterminism asserts a certain difference between the future and the past (that one has always APnpPnNp, but not always AFnpFnNp), which is not at all the same thing as a difference between the earlier and the later. (See Ploug and Øhrstrøm 2012)

(Here Prior is using the Polish notation he preferred. Furthermore, he introduced metric tense operators, $P(n)$ for "it was the case $n$ time units ago that" and $F(n)$ "it will be the case in $n$ time units that". The formulae in terms of modern standard notation are $P(n) p \vee P(n) \sim p$ and $F(n) p \vee F(n) \sim p$, respectively.)

Prior's point is that the notion of indeterminism can be stated in a precise manner using tense-logic. Using a Peircean model he pointed out that if indeterminism holds, then at some moment of time and for some $n$ and $p$ the proposition, $F(n) p \vee F(n) \sim p$, will not be true, whereas $P(n) p \vee P(n) \sim p$ will be true in all cases. Using an Ockhamistic model indeterminism would instead have to be explained in terms of a denial of the disjunction, $\square F(n) p \vee \square F(n) \sim p$. It is of course important and crucial that basic ideas such as determinism and indeterminism can be explained in terms of a tense-logical formalism. First of all, this possibility means that the basic and classical ideas regarding time and existence can be made clear. Secondly, it means that it 
becomes possible to explore the conceptual consequences of the ideas in a very precise manner.

Prior suggested that the tense-logical approach (including instant propositions) can be used in general whenever we want to explore questions within the study of time. This obviously should be seen in the light of Prior's more general understanding of time. In his Past, Present and Future (p. 67) he referred to Ludwig Wittgenstein's view on time expressed in the Blue Book. Unfortunately, the reference is only in passim, but what he had in mind was probably this statement:

And when we are worried about the nature of thinking, the puzzlement which we wrongly interpret to be one about the nature of a medium is a puzzlement caused by the mystifying use of our language. This kind of mistake recurs again and again in philosophy; e.g. when we are puzzled about the nature of time, when time seems to us a queer thing. We are most strongly tempted to think that here are things hidden, something we can see from the outside but which we can't look into. And yet nothing of the sort is the case. It is not new facts about time which we want to know. All the facts that concern us lie open before us. But it is the use of the substantive "time" which mystifies us. If we look into the grammar of that word, we shall feel that it is no less astounding that man should have conceived of a deity of time than it would be to conceive of a deity of negation or disjunction. (Wittgenstein 1933, p. 10)

Wittgenstein's point is that the use of the substantive "time" leads us to believe that time is an object. Referring to Wittgenstein's view that this approach to time is mistaken, Prior wrote:

For if taken literally, statements like 'Time will have an end', 'Time is circular', 'Time is continuous', etc., suggest that there is some monstrous object called Time, the parts of which are arranged in such-and-such ways (a common idea is that of a string on which events are strung like beads); and such statements cease to carry such suggestions when they are interpreted as short-hand for statements which do not even appear to mention any such entity, but simply talk about what will have been the case, etc. (Prior 1967, p. 75)

This paradigmatic statement regarding the study of time can be summarised in Prior's claim that tense-logic may be seen as "giving cash value of assertions about time" (Prior 1967, p. 74).

Prior was obviously aware of the problem from special relativity as pointed out by Kripke, but he could not accept the idea of having one logic for the subjective or psychological approach to time and another logic for the objective and scientific approach to time. We have already noted Prior's emphasis on interdisciplinary studies and its underlying assumption of one and the same kind of rationality at the root of all scientific disciplines. Consequently, Prior found that our goal should be one common logic of time covering all disciplines and aspects of reality. Assuming that this language should be tense-logic (conceived according to the third or fourth grade of tense-logical involvement), we clearly have to deal with the problem from relativistic physics as well as all other such problems and challenges. Prior discussed the problem 
several times (see. e.g. Prior 1967, p. 203 ff.), and it has been a subject of investigation ever since. In their paper Müller and Strobach (2012) have presented a careful account of the status within the field showing that there are in fact several ways to combine Prior's tense-logical approach to time with the special theory of relativity.

One other main problem in Prior's logic and philosophy of time has to do with the relation between time and modality. If time is conceived as branching, it involves the notion of possible futures. But does this mean that the concept of possibility can be derived from the very concept of branching time? According to the 'fourth grade of tense-logical involvement', this question should be answered in the affirmative, whereas according to the third grade of tense-logical involvement, possibility should be understood as conceptually primitive-just as the tenses themselves (see Prior 2003a).

It is obvious that Prior's tense-logical approach to time is very powerful, enabling the A-series and its competitors to be studied in a precise manner. Prior established a general framework for the study of time. On the other hand, there are also many unresolved questions and clearly a need for further development of this paradigm. We suggest that these developments will be informed and inspired by the study of Prior's writings concerning the tense-logical paradigm for the study of time.

As we have seen Prior realised that the classical arguments from the doctrine of divine foreknowledge to the denial of the doctrine of free choice could actually be formulated in tense-logical terms (cf. Prior 1967, 2003b). With his new apparatus of tense logic, it became possible to explore whether there are formal logical systems according to which one can consistently hold both doctrines. Prior described at least two alternative systems, which he as mentioned above termed the Peircean and the Ockhamistic systems. Both of these allow for the acceptance of at least a version of the doctrine of divine foreknowledge as well as the doctrine of free choice (1967, p. $113 \mathrm{ff}$ ). It is worth noting how he kept seriously investigating these issues long after he had given up what one might call his personal interest in them-that is, long after he had left his denomination and become an agnostic. In our opinion, this strongly emphasises his belief in rational thinking as a possibility and requirement across the full range of intellectual disciplines.

Overall, Prior demonstrated that tense-logic is able to connect discussions in theology, metaphysics, philosophy, logic and physics. Moreover, he showed that tense-logic is relevant to the study of language. It seems that he even foresaw, though perhaps only dimly, its most famous application of all, namely its later role in computer science. In his undated note, "A Statement of Temporal Realism", he wrote:

There are clear, hard structures for formal logicians to discover in the world of change and temporal succession. There are practical gains to be had from this study too, for example in the representation of time-delay in computer circuits, but the greatest gain that a logic of tenses brings is the accurate philosophical description of the reality of the passage of time. (Prior 2014b, p. 2)

Furthermore, in Past, Present and Future Prior almost predicted the practical application in computer science of tense-logical systems:

The usefulness of systems of this sort does not depend on any serious metaphysical assumption that time is discrete; they are applicable in limited fields of 
discourse in which we are concerned only with what happens next in a sequence of discrete states, e.g. in the workings of a digital computer. (Prior 1967 p. 67)

\section{Conclusion}

Prior's writings should clearly be studied for historical reasons-especially but not only the writings concerned with his important inventions of temporal logic and hybrid logic. But his works also deserve present-day systematic attention for more general reasons. Later refinements within logic notwithstanding, Prior's exceptional clarity on the most fundamental questions secures a lasting place for his works. His reflections on the possible limitations of formalisation are even more relevant today than in Prior's own time. Likewise his thoughts on the interdisciplinary nature of logic are very relevant to today's world of increasingly permeable academic boundaries.

In this paper we made a number of references to Prior's Nachlass. It seems obvious that his correspondence and the papers he left can give us an important key to a deeper understanding of the tense-logical paradigm for the study of time on which he was working from 1953 and right up to his untimely death in 1969.

In the two or three decades following Prior's death, his tense-logic was entirely at the focus of assessing his work, and his many "other interests" were seen much as just that-other interests, more or less loosely connected (quite explicitly so in several papers, see for instance Anthony Kenny's great memorial paper 'A. N. Prior', 1971). In particular, his early work in theology was seen as being an entirely separate phase without connection to his later work. However, the last fifteen years of Prior studies - and not least work done on his Nachlass - have drawn an increasingly strong picture of a distinct overall fabric to Prior's thought. We have tried to trace some of the underlying methodological tenets of Prior's work. These tenets, active in all aspects of Prior's work, at least in part explain its overall coherent and connected character. (The other part of the explanation would be, in our opinion, affinities between most of the subject matters.) However, Prior himself never programmatically stated "a philosophy" or tried to lay out a philosophical system. In so far as something of this kind can indeed be attributed to him, it must be carefully pieced together from various remarks (some of which seem almost "in passim"), and from unpublished material in his Nachlass. Why is that so? In the previously quoted 1942 diary entry, Prior made a further remark which may shed light on this point. To be true, we cannot know for sure whether he would have given the same answer throughout his long career after 1942, but his later work is certainly quite consistent with the following quote:

I have always been a foe of "dilettantism," of piecing together a "view of the universe" out of various scraps of knowledge and putting the whole thing forward as an intellectual construction worth looking at. The people who throw real light on "life in general" are the people who don't make "life in general" their subject, but make themselves experts in a particular line and then drops gems out of the apparently useless mass of knowledge they've acquired. For instance, much more light is shed on the bearings of theology on politics by a "pure theologian" like Barth than by these more popular guys who make a vague study of "theology and culture" a special subject—e.g. Berdyaev. And much more light is shed on 
the bearing of psychoanalysis on religion by a "pure psychoanalyst" like Freud than by a so called "social and abnormal psychologist" like Jung. They're all second-rates, these Jungs and Berdyaevs and Huxleys and similar putters-forth of "views of the world". (2014c)

Prior's view seems to be that if we want to explore and understand a general and fundamental aspect of life_-such as time-we should not make "life in general" our subject. We should rather study a specific and relevant approach and technique in as many details as possible. In this way we may then find the key to a proper understanding of the general concept. Prior has argued that a careful and systematic study of tenselogic can give rise to very important insights regarding time.

In the study and development of tense-logic it will be useful to take an interdisciplinary approach. In fact the study of tense-logic can obtain inspiration from several disciplines (psychology, theology, physics, computer science etc.). In trying to obtain this inspiration we should look for formal structures (i.e. systems). Furthermore, we should try to explain the formalities of these structures in terms of tense-logic. If Prior is right, this paradigm for the study of time will be the key to a proper understanding of time as a general aspect of life and existence. When Prior died in 1969 he was still struggling to clarify more precisely what his approach would mean and many of his attempts in this regard were still tentative and unfinished. The challenge for anyone interested in the tense-logical paradigm for the study of time will be to continue Prior's work and to explore the qualities and the potential of the further development of this paradigm.

Open Access This article is distributed under the terms of the Creative Commons Attribution 4.0 International License (http://creativecommons.org/licenses/by/4.0/), which permits unrestricted use, distribution, and reproduction in any medium, provided you give appropriate credit to the original author(s) and the source, provide a link to the Creative Commons license, and indicate if changes were made.

\section{References}

Bergson, H. (1950). Time and free will, Authorised Translation by F. L. Pogson (First Impression 1910). London: George Allen \& Unwin Ltd.

Blackburn, P. (1993). Nominal tense logic. Notre Dame Journal of Formal Logic, 34(1), 58-63.

Borghini, A., \& Torrengo, G. (2013). The metaphysics of the thin red line. In F. Correia \& A. Iacona (Eds.), Around the tree. Synthese library. Heidelberg: Springer.

Braüner, T. (2011). Hybrid logic. Stanford Enclopedia of Philosophy, Winter 2011 Edition.

Copeland, B. J. (Ed.). (1997). Logic and reality. Essays on the Legacy of Arthur Prior. Oxford: Clarendon Press.

Grimshaw, M. (2002). The prior Prior: Neglected early writings of Arthur N. Prior. The Heythrop Journal, 43(4), 480-495.

Grimshaw, M. (2013). A. N. Prior on James Joyce. Philosophical Inquiries, 1(1), 193-202.

Hasle, P. F. V., (2012). The problem of predestination: as a prelude to A. N. Prior's tense logic. Synthese, 188(3), 331-347. (An earlier version of this paper was published on the Prior web-site in 1997).

Hasle, P. (2003). Life and work of Arthur Prior: An interview with Mary Prior. In P. Hasle, P. Øhrstrøm, J. Copeland, \& T. Braüner (Eds.), Papers on time and tense (2nd ed., pp. 293-310). Oxford: oxford University Press.

Jakobsen, D. (2013). Arthur Norman Priors bidrag til metafysikken (Trans: Arthur Norman Prior's contribution to Metaphysic), Ph.D. Thesis, Aalborg University. 
Kenny, A. (1971). Arthur Norman Prior (1914-1969). In Proceedings of the British Academy (pp. 321-349).

Kołakowski, L. (1956). Marxismus und personalistischer Freiheitsbegriff. Berlin: Verlag Junge Welt.

McTaggart, J. M. E. (1908). Unreality of time. Mind: A Quarterly Review of Psychology and Philosophy, $17,456-473$.

Müller, T., \& Strobach, N. (2012). A letter on the present state of affairs Prior, indeterminism and relativity 40 years later. Synthese, 188(3), 469-485.

Øhrstrøm, P. (2016). The concept of time: A philosophical and logical perspective. In Mölder Bruno, Arstila Valtteri, \& Øhrstrøm Peter (Eds.), Philosophy and psychology of time (pp. 9-27). New York: Springer Publishing Company. (Studies in Brain and Mind, Vol. 9).

$\emptyset$ hrstrøm, P. (2011). Towards a common language for the discussion of time based on prior's tense logic. Lecture Notes in Computer Science, 6789, 46-57.

Øhrstrøm, P. (2014). What William of Ockham and Luis de Molina Would Have Said to Nuel Belnap: A discussion of some arguments against the thin red line. In T. Müller (Ed.), Nuel Belnap on indeterminism and free action. Berlin: Springer-Verlag $\mathrm{GmbH}$.

Øhrstrøm, P., \& Hasle, P. (1995). Temporal logic. From Ancient ideas to artificial intelligence. Dordrecht: Kluwer.

Øhrstrøm, P., Zeller, J., \& Sandborg-Petersen, U. (2012). Prior's defence of Hintikka's theorem. A discussion of Prior's 'The logic of obligation and the obligations of the logician. Synthese, 188, 449-454.

Ploug, T., \& Øhrstrøm, P. (2012). Branching time, indeterminism and tense logic. Synthese, 188(3), 367-379.

Prior, A. N. (1934a). Athanasius Contra Mundum. Open Windows, 4, s.6-s.7.

Prior, A. N. (1934b). Christ and human history. Open Windows, 1, s.18-s.19.

Prior, A. N. (1935). Logic and dogma. Open Windows, 5, s.19.

Prior, A. N. (1942). Can religion be discussed? Australasian Journal of Philosophy, 20(2), 141-151.

Prior, A. N. (1946). The reformers reformed: Knox on predestination. The Presbyter, 4, 19-23.

Prior, A. N. (1947). Supralapsarianism. The Presbyter, 5, 19-22.

Prior, A. N. (1955). Is necessary existence possible? Philosophy and Phenomenological Research, 15(1955), $545-547$.

Prior, A. N. (1959). Creation in science and theology. Southern Stars, 18, 82-89.

Prior, A. N. (1962). The formalities of omniscience. Philosophy, 37, 114-129.

Prior, A. N. (1967). Past, present and future. Oxford: Oxford University Press.

Prior, A. N. (1976). What is Logic? In P. T. Geach \& A. J. P. Kenny (Eds.), Papers in logic and ethics. Amherst, MA: University of Massachusetts Press.

Prior, A. N. (2003a). In P. Hasle, P. Øhrstrøm, J. Copeland, \& T. Braüner (Eds.), Papers on time and tense, 2nd Edition. Oxford: Oxford University Press. (The 1st edition was published in 1968).

Prior, A. N. (2003b). The formalities of omniscience. In P. Hasle, P. Øhrstrøm, J. Copeland, \& T. Braüner (Eds.), Papers on time and tense (pp. 39-58). Oxford: Oxford University Press.

Prior, A. N. (2012). "Faith, unbelief and evil: A fragment of a dialogue". Edited by D. Jakobsen. Synthese, 188(3), From a logical angle. Some Studies in A. N. Prior's Ideas on Time, Discourse, and metaphysics, pp. 381-397.

Prior, A. N. (2014a). Some free thinking about time. The Nachlass of A. N. Prior. http://nachlass.prior.aau. dk. (An earlier version has been published in Copeland 1997).

Prior, A. N. (2014b). A statement of temporal realism. The Nachlass of A. N. Prior. http://nachlass.prior. aau.dk/. (An earlier version has been published in Copeland 1997).

Prior, A. N. (2014c). "Diary entry March 25 1942”. The Nachlass of A. N. Prior. http://nachlass.prior.aau. $\mathrm{dk} /$.

Prior, A. N. (2014d)."Reactions to Determinism". The Nachlass of A. N. Prior. http://nachlass.prior.aau. $\mathrm{dk} /$.

Prior, A. N. (2014e). Determinism in philosophy and theology. The Nachlass of A. N. Prior. http://nachlass. prior.aau.dk/.

Prior, A. N. (2014f). The logic of obligation and the obligations of the logician. The Nachlass of A. N. Prior. http://nachlass.prior.aau.dk/.

Prior, A. N. (2016). The craft of logic, part I. The Nachlass of A. N. Prior. http://nachlass.prior.aau.dk/.

Smart, J. J. C. (1949). The river of time. Mind, 58, 483-494.

Wittgenstein, L. (1933-1934). What is the meaning of a word? Ludwig Wittgenstein's Blue Book, undated Box 11, Folder 12, Rose Rand Papers, 1903-1981, ASP.1990.01, Archives of Scientific Philosophy, Special Collections Department, University of Pittsburgh. 